\title{
The 48th Liege colloquium: submesoscale processes: mechanisms, implications, and new frontiers
}

\author{
Alexander Barth ${ }^{1}$ (D) . Amala Mahadevan ${ }^{2} \cdot$ Ananda Pascual $^{3} \cdot$ Simon Ruiz $^{3} \cdot$ Charles Troupin $^{1}$
}

Received: 18 May 2018 / Accepted: 24 May 2018 / Published online: 18 June 2018

(C) Springer-Verlag GmbH Germany, part of Springer Nature 2018

The 48th International Liège Colloquium on Ocean Dynamics took place from the 23 to the 27 May, 2016, in the Academic Room of the University of Liège (Belgium). Every year, the Colloquium addresses a cutting-edge topic in Ocean Science with the goal to foster discussions and collaborations among scientists from all around the world.

This edition aimed to advance our collective understanding of submesoscale processes, their mechanistic functioning, relevance, and implications across a range of oceanic disciplines. Discussions included observational, modeling, and theoretical approaches for elucidating submesoscale phenomena.

This 48th edition was a success with 199 participants (Fig. 1) from 25 countries, 72 oral presentations, 8 keynote talks, and 143 posters, distributed over 7 topical sessions. All sessions are represented in the present topical collection of Ocean Dynamics.

Multiscale interactions-energy cascade, impact of submesoscales on other scales The topical collection includes four papers from this session. Lozovatsky et al. (2017) present microstructure measurements on the North Carolina shelf and across the Gulf Stream front. The vertical eddy diffusivity is described from these measurements and parameterization of the diffusivity for various mesoscale dynamical conditions was proposed.

Nagai and Clayton (2017) study nitrate interleaving structures in oligotrophic surface waters south of the Kuroshio

\footnotetext{
Responsible Editor: Jörg-Olaf Wolff

Alexander Barth

A.Barth@ulg.ac.be

1 GeoHydrodynamics and Environmental Research (GHER), University of Liège, Liège, Belgium

2 WHOI, Woods Hole, MA 02543, USA

3 IMEDEA (CSIC-UIB), Esporles, Spain
}

Extension Front. These structures are produced by a realistic, high-resolution $(2 \mathrm{~km})$ numerical simulation and their formation mechanism is discussed.

Sasaki et al. (2017) describe the seasonality of the kinetic energy studied by comparing model results of different resolutions. In particular, the contribution of the submesoscale variability to the kinetic energy is discussed. The authors found that in regions with high kinetic energy, frontal mixed-layer instabilities are the dominant process for the generation of submesoscale flow structures in winter.

A similar approach is also used by Pérez and Calil (2017) to study the Caribbean Upwelling System. A system of models at different spatial resolutions is implemented to highlight the impact of submesoscale processes on the regional kinetic energy cascade. The authors conclude among others that submesoscale dynamics play a key role in modulating the eddy kinetic energy and the energy cascade within the Caribbean Sea.

Mixed layer and frontal instabilities-dynamical understanding, Lagrangian view, lateral mixing Three papers from this session are presented here including both theoretical and observational studies. Stamper and Taylor (2017) provide a linear stability analysis of the Eady model with a focus on three-dimensional mixed modes. They explore the transition from symmetric to baroclinic instability using a high-resolution numerical simulation showing the highly variable vertical velocities in frontal areas and significant transfer of energy to small scales.

In Sentchev et al. (2017), velocity observations from various platforms (high-frequency radars, surface drifting buoys and a drifting acoustic Doppler current profiler) are used to study the 3D flow field and the velocity variability due to wind forcing in the Northwestern Mediterranean Sea.

Another study from the Northwestern Mediterranean Sea presents the results of the LAgrangian Transport EXperiment (LATEX) aiming to better understand the impact of coastal mesoscale and submesoscale physical processes on 


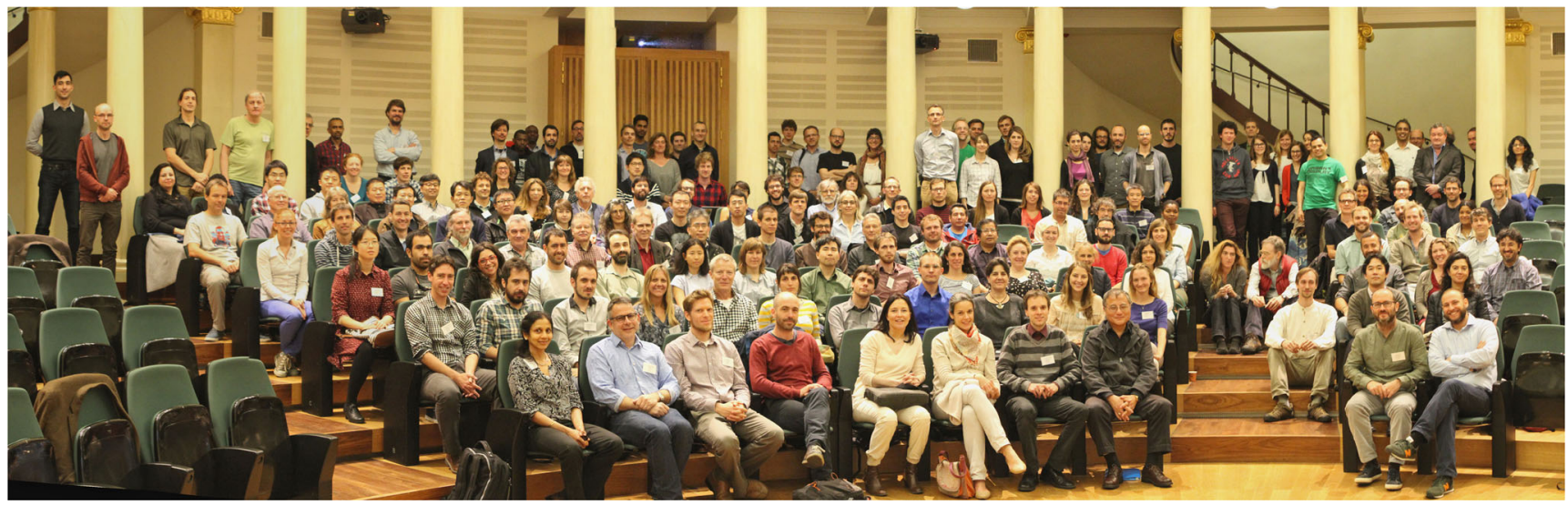

Fig. 1 Participants of the 48th International Liège Colloquium

circulation dynamics, cross-shelf exchanges, and biogeochemistry in the Gulf of Lion. Nested numerical model simulations and multi-platform field experiments are used to study the generation processes of eddies and quantification of horizontal mixing and cross-shelf exchanges (Petrenko et al. 2017).

Internal waves and wave-front/eddy interactions For this session, the topical collection includes a review paper of Thomas (2017) discussing the impact of lateral density gradients on internal waves based on theoretical calculations and numerical simulations. In particular, the paper shows the energy dissipation due to the interactions between balanced currents and near-inertial waves.

Remote sensing of submesoscale dynamics-surface topography, ocean temperature, and color In preparation for the high-resolution altimetry mission SWOT (Surface Water and Ocean Topography), Durán Moro et al. (2017) propose a Kalman Filter scheme tailored for the assimilation of the high-resolution observations of the sea surface height to reconstruct mesoscale features simulated by numerical models. This scheme is tested in a twin experiment in the Solomon Sea region.

Impact of atmospheric surface forcing, sea ice, river plumes and waves on mixed layer and submesoscale turbulence Jensen et al. (2018) show the results of a high-resolution coupled atmosphere-ocean-wave model in the Bay of Bengal where different cases of oceanic submesoscale features are studied (heavy rainfall and intense downdrafts, solitary-like waves and strong salinity gradients at river outflows).

\section{Physical-biological interactions-implications for biogeo-} chemistry, productivity, export, diversity, and transport In this session, Olita et al. (2017) present bio-physical glider measurements in the Eastern Alboran Sea studying mesoscale and submesoscale upwelling carrying phytoplankton patches and show the relevance of fronts in triggering primary production at the deep chlorophyll maximum level.

Another high-resolution observational study addresses the transport of phytoplankton through baroclinic instability (Allen 2017) and the importance of the conservation of potential vorticity in producing long, thin filaments of phytoplankton populations is highlighted.

High-resolution nested model simulations are used in Calil (2017) to simulate the impact of submesoscale processes in the subduction along the South Atlantic Subtropical Front. Only the high-resolution model was able to represent the intense vertical velocities and the wind-driven subduction process.

Coastal submesoscale dynamics - interaction with topography and bottom boundary Delandmeter et al. (2017) present the results of an unstructured-mesh, finite element model for geophysical and environmental flows, to simulate a rich submesoscale field of tidal jets, eddies, and shear layers. The results are validated using a pair of $2-\mathrm{m}$ resolution, visible-band images that were acquired by the WorldView-3 satellite.

Potential vorticity is also a key concept in the study of Rogé et al. (2017) who propose a dynamical interpolation scheme for SSH based on the use of synthetic data from an ocean model. It is intended to interpolate the SSH signal in the time between two satellite revisits in preparation for the SWOT mission.

The Jacques Nihoul Poster Award (chosen by the scientific committee) was given to Jacob M. Steinberg for his work entitled "The Evolution of a California Undercurrent Submesoscale Eddy (Cuddy)." The public poster award was given to Marina Duran Moro (LGGE, Grenoble, France) for her work on "3D reconstruction of mesoscale flows using observations of satellite high resolution data: twin experiments with a numerical model of the Solomon Sea." As 
mentioned before, her work is also present in this topical collection. Most of the talks were followed by particularly lively discussions and special attention was given to foster the interaction between young and senior scientists (by organizing joint lunch breaks) which made the colloquium for many a memorable event.

Acknowledgments In the name of the scientific committee and of the organizing committee, we want to thank the sponsors of this event for their valuable support: Intergovernmental Oceanographic Commission of UNESCO, SOCIB (Spain), Région Wallonne (Belgium), University of Liège (Belgium), ESA, CNES (France), NASA (USA), F.R.S.FNRS (Belgium), IUGG, EUMETSAT, SCOR, and the Copernicus Marine Environment Monitoring Service.

\section{References}

Allen JT (2017) Marine algae are taught the basics of angular momentum. Ocean Dyn 67(11):1429-1442. https://doi.org/10.1007/s10236017-1094-8

Calil PHR (2017) Wind-induced subduction at the south atlantic subtropical front. Ocean Dyn 67(10):1351-1365. https://doi.org/ 10.1007/s10236-017-1090-z

Delandmeter P, Lambrechts J, Marmorino GO, Legat V, Wolanski E, Remacle JF, Chen W, Deleersnijder E (2017) Submesoscale tidal eddies in the wake of coral islands and reefs: satellite data and numerical modelling. Ocean Dyn 67(7):897-913. https://doi.org/ 10.1007/s10236-017-1066-z

Durán Moro M, Brankart JM, Brasseur P, Verron J (2017) Exploring image data assimilation in the prospect of high-resolution satellite oceanic observations. Ocean Dyn 67(7):875-895. https://doi.org/ 10.1007/s10236-017-1062-3

Jensen TG, Shulman I, Wijesekera HW, Anderson S, Ladner S (2018) Submesoscale features and their interaction with fronts and internal tides in a high-resolution coupled atmosphere-ocean-wave model of the bay of bengal. Ocean Dyn 68(3):391-410. https:// doi.org/10.1007/s10236-018-1136-x

Lozovatsky I, Planella-Morato J, Shearman K, Wang Q, Fernando HJS (2017) Vertical mixing and elements of mesoscale dynamics over north carolina shelf and contiguous gulf stream waters. Ocean Dyn 67(6):783-798. https://doi.org/10.1007/s10236-017-1059-y

Nagai T, Clayton S (2017) Nutrient interleaving below the mixed layer of the kuroshio extension front. Ocean Dyn 67(8):1027-1046. https://doi.org/10.1007/s10236-017-1070-3

Olita A, Capet A, Claret M, Mahadevan A, Poulain PM, Ribotti A, Ruiz S, Tintoré J, Tovar-Sánchez A, Pascual A (2017) Frontal dynamics boost primary production in the summer stratified mediterranean sea. Ocean Dyn 67(6):767-782. https://doi.org/10.1007/ s10236-017-1058-z

Pérez JGC, Calil PHR (2017) Regional turbulence patterns driven by meso- and submesoscale processes in the caribbean sea. Ocean Dyn 67(9):1217-1230. https://doi.org/10.1007/s10236-017-1079-7

Petrenko AA, Doglioli AM, Nencioli F, Kersalé M, Hu Z, d'Ovidio F (2017) A review of the latex project: mesoscale to submesoscale processes in a coastal environment. Ocean Dyn 67(3):513-533. https://doi.org/10.1007/s10236-017-1040-9

Rogé M, Morrow R, Ubelmann C, Dibarboure G (2017) Using a dynamical advection to reconstruct a part of the ssh evolution in the context of swot, application to the mediterranean sea. Ocean Dyn 67(8):1047-1066. https://doi.org/10.1007/s10236-017-1073-0

Sasaki H, Klein P, Sasai Y, Qiu B (2017) Regionality and seasonality of submesoscale and mesoscale turbulence in the north pacific ocean. Ocean Dyn 67(9):1195-1216. https://doi.org/10.1007/s10236-0171083-y

Sentchev A, Forget P, Fraunié P (2017) Surface current dynamics under sea breeze conditions observed by simultaneous hf radar, adcp and drifter measurements. Ocean Dyn 67(3):499-512. https://doi.org/ 10.1007/s10236-017-1035-6

Stamper MA, Taylor JR (2017) The transition from symmetric to baroclinic instability in the eady model. Ocean Dyn 67(1):65-80. https://doi.org/10.1007/s10236-016-1011-6

Thomas LN (2017) On the modifications of near-inertial waves at fronts: implications for energy transfer across scales. Ocean Dyn 67(10):1335-1350. https://doi.org/10.1007/s10236-017-1088-6 